\title{
Da temporalidade imanente ao tempo objetivo do mundo em Husserl ${ }^{1}$
}

\author{
Marcelo Rosa Vieira *
}

Resumo: O texto analisa o modo como a teleologia, na concepção de Husserl, opera na subjetividade conforme a forma originária da temporalidade. Apresentamos uma breve discussão dos textos em que o tempo é descrito como estrutura interna do ser da consciência, concentrando-nos nas Vorlensungen zur Phänomenologie des inneren Zeitbewusstseins. O objetivo é compreender a teoria transcendental desenvolvida por Husserl para resolver os problemas relacionados à possibilidade do conhecimento no tempo, e o modo como a temporalidade do mundo é constituída teleologicamente pela consciência a partir da temporalidade imanente.

Palavras-chave: Fenomenologia, Temporalidade, Teleologia, Subjetividade.

\footnotetext{
${ }^{1} \mathrm{O}$ presente texto é resultado parcial da pesquisa de doutorado realizada no Instituto de Filosofia (IFILO) da Universidade Federal de Uberlândia, sob a orientação do professor Alexandre Guimarães Tadeu de Soares.

${ }^{*}$ Doutorando pelo Programa de Pós-Graduação em Filosofia da Universidade Federal de Uberlândia (2019-). Possui graduação em Pedagogia pela Universidade Federal de Juiz de Fora (2012), mestrado em Filosofia pela Universidade Federal de Uberlândia (2016) na linha de pesquisa "Ontologia e Teoria do Conhecimento". E-mail: marcelroust@hotmail.com Orcid: https://orcid.org/0000-0002-5168-9448
} 


\section{De la temporalité immanente au temps objectif du monde chez Husserl}

Resumé: Le texte analyse comment la téléologie, dans la conception de Husserl, opère sur la subjectivité selon la forme originelle de la temporalité. Nous présentons une brève discussion des textes dans lesquels le temps est décrit comme la structure interne de l'être de conscience, en nous concentrant sur le Vorlensungen zur Phänomenologie des inneren Zeitbewusstseins. L'objectif est de comprendre la théorie transcendantale développée par Husserl pour résoudre les problèmes liés à la possibilité de la connaissance dans le temps, et la manière dont la temporalité du monde se constitue téléologiquement par la conscience de la temporalité immanente.

Mots-clés: Phénoménologie, Temporalité, Téléologie, Subjectivité.

\section{Introdução}

A análise da consciência do tempo é uma das questões mais delicadas de toda a fenomenologia. Trata-se, nas palavras de Husserl, de uma antiquíssima cruz da psicologia descritiva e da teoria do conhecimento, a qual impõe uma esfera fechada de problemas de excepcional dificuldade; de modo que ainda hoje se pode afirmar com Santo Agostinho: Quid est ergo tempus? si nemo a me quaerat, scio, si 
quaerenti explicare velim, nescio. (Que é, pois, o tempo? Se ninguém me pergunta, eu sei; mas se quiser explicar a quem indaga, já não sei) ${ }^{2}$. O paradoxo que se revela em tal constatação é o fato de que o tempo, por um lado, é a coisa mais óbvia e conhecida de todas, mas, por outro lado, ele nos enreda nas mais estranhas dificuldades assim que procuramos conduzir essa obviedade a uma clara evidência. A obviedade torna-se então um enigma.

Os problemas relacionados à consciência do tempo podem de início ser colocados em três níveis diferentes: a (I) percepção dos objetos temporais; (II) a percepção do tempo em si mesmo; e (III) a temporalidade da própria percepção. O que leva a uma excruciante ambiguidade entre a temporalidade imanente dada na consciência e a temporalidade dos objetos no mundo: qual é a correta relação entre o tempo objetivo e a consciência subjetiva do tempo? Como o objeto temporal pode ser constituído subjetivamente? Qual é o conteúdo e o teor fenomenológico das vivências temporais?

As Lições de 1905 Para uma fenomenologia da consciência interna do tempo (publicadas como husserliana $\mathrm{X}$ ) são o primeiro trabalho de Husserl a se ocupar de tais questões. Merleau-Ponty considera esse texto o mais belo de toda fenomenologia. No entanto, isso não significa que as Lições sejam o texto privilegiado para a compreensão da doutrina husserliana do tempo. As razões para isso são

\footnotetext{
${ }^{2}$ AGOSTINHO. Confessiones, Lib. XI, cap. 14. [Nota da Hua.]
} 
várias. Em primeiro lugar, as Lições são compostas de duas partes, A e $\mathrm{B}$, das quais somente a primeira parte, de 130 páginas, possui uma coerência redacional e sistemática, sendo que a parte $\mathrm{B}$, de 248 páginas, não é mais do que um conjunto de manuscritos fragmentados, anotações e reflexões que não receberam uma articulação interna. A tarefa de reunir num todo coerente as duas partes está ainda para ser feita; além disso, a falta de unidade entre elas dificulta uma necessária interpretação de conjunto. Em segundo lugar, a organização da parte A das Lições em seções e capítulos não é de autoria do próprio Husserl, e sim de Edith Stein, sua assistente na época; o que significa que a forma e a composição da obra não foram concebidas pelo próprio filósofo. Em terceiro lugar, as Lições, que datam de 1905 e que foram concluídas em 1910, só foram publicadas em 1928 por Martin Heidegger, 18 anos mais tarde. Coloca-se então o problema: por que o silêncio sobre a obra por quase duas décadas? Husserl admite em diversas ocasiões que ele julgava as Lições um trabalho incipiente e imaturo não digno de ser publicado. O que o fez, porém, mudar de ideia em 1928, e permitir sua publicação? Mas Husserl ele mesmo confessa que as Lições não constituem seu texto principal sobre o problema do tempo, ao pedir a Roman Ingarden nos anos 20 que preparasse para publicação um conjunto de manuscritos estenografados - em torno de 600 páginas que ele chamou de sua obra capital sobre a questão do tempo. Tratavase dos manuscritos de Bernau, (Die Bernauer Manuskripte über das 
Zeitbewusstsein), um conjunto de apontamentos que datam de 19171918 e que se ocupa dos problemas mais difíceis da fenomenologia.

Nesses manuscritos, Husserl está preocupado em elevar a problemática do tempo ao nível da fenomenologia transcendental, daí ele retoma e desenvolve sua fenomenologia anterior esboçada nas Lições. A obra se divide numa Introdução sobre “O problema do tempo transcendental"; numa primeira seção consagrada à “Análise do tempo imanente"; numa segunda seção sobre "A constituição do tempo imanente"; e numa terceira seção sobre "A autoconstituição da consciência interna do tempo". São apresentadas novas intuições decisivas que dizem respeito principalmente à consciência do tempo "protencional" orientada para o futuro em seu entrelaçamento com a consciência "retencional" do passado. Outros assuntos são também tratados como: (I) o ego individual como mônada e a intersubjetividade transcendental, na qual um tempo intersubjetivo é sempre constituído para todos; (II) o enfrentamento da aporia aristotélica da regressão ao infinito; (III) a definição especificamente noemática das modalidades do tempo, que levaria Husserl a uma fenomenologia da individuação. Pela primeira vez, Husserl também dedica investigações aprofundadas à conexão entre a corrente temporal primordial e a autotemporalização. Os textos constituem em suma uma fenomenologia da consciência do tempo em uma nova perspectiva "genética", que não é apenas baseada 
no paradigma da percepção, mas também se volta para os atos da memória e da fantasia.

Embora o texto das Lições de 1905 constitua uma etapa prévia cujos resultados são provisórios em vista dos estudos posteriores, isso não diminui sua importância para a compreensão da problemática e da abordagem fenomenológica fundamental da questão do tempo. Husserl ele mesmo declara numa nota em Lógica Formal e Transcendental que as Lições para uma fenomenologia da consciência interna do tempo haviam apreendido e explicitado o essencial da questão. Por isso sua relevância não deve ser menosprezada.

Apresentando de forma concisa o conteúdo da obra, pode-se dizer que a investigação que comanda as Lições é a da "origem do tempo" (Ursprung der Zeit), tomada como pergunta gnosiológica e não como uma interrogação sobre a origem psicológica da "nossa" representação. O seu primeiro passo na fenomenologia do tempo consiste num préesboço da Epoché, a saber, numa "eliminação do tempo objetivo". Esta eliminação é uma mudança de atitude essencial para um exame fenomenológico. O que deve ser colocado fora de circuito nessa exclusão são as suposições, as crenças e estipulações prévias sobre o tempo objetivo. No entanto, elas não são declaradas falsas: o fenomenólogo apenas tem que se abster de julgá-las. Portanto, o assunto da análise fenomenológica do tempo não será o tempo 
universal, o tempo cronológico real, o tempo da natureza no sentido das ciências naturais nem o da psicologia como a ciência natural da alma.

\section{O problema do tempo na tradição}

O problema do tempo pode ser meditado, basicamente, a partir de dois tipos de consideração filosófica: de um ponto de vista gnosiológico, relacionado ao conhecimento das coisas no tempo; e de um ponto de vista ontológico, relacionado ao ser ou existência das coisas temporais.

Na tradição, há duas posições clássicas que se opõem no que diz respeito ao estatuto ontológico do tempo. A primeira delas é o mobilismo radical de Heráclito, para quem o devir é uma característica estrutural cosmológica. Segundo esse princípio, todo universo encontra-se num estado de perpétuo escoamento, tudo flui, tudo se move (panta rhei), logo, não é possível banhar-se duas vezes no mesmo rio. Isso significa que não é possível atingir o conhecimento pelos sentidos, pois estes captam apenas a aparência das coisas, as quais não cessam de mudar.

A segunda posição é a do imobilismo radical de Parmênides, para quem o devir não existe, pois o ser, que engloba todas as coisas, é imóvel, uno, imutável e eterno. De acordo com esse princípio, "o ser é” e "o nada não é”, portanto, não há passado nem futuro, pois o passado, sendo aquilo que foi e não é mais, é um nada, e o futuro, sendo aquilo 
que não é e que ainda será, é também um nada. O nada, pela sua própria definição, não existe. Da definição do ser, por sua vez, segue-se que ele existe necessariamente como um perpétuo presente, uma esfera totalmente fechada, em eterno repouso, sempre homogênea e sempre idêntica a si mesma. O tempo, que é atestado pelos nossos sentidos, não passa de uma aparência sem valor de realidade.

As duas posições, que são diametralmente opostas na ordem do ser, cruzam-se, porém, numa mesma concepção quanto à ordem do conhecer, pois tanto Heráclito quanto Parmênides entendem que a verdade situa-se acima do aspecto temporal das coisas. Para alcançá-la gnosiologicamente, a razão humana deve elevar-se para além dos sentidos e captar o Logos imutável que governa o mundo.

Platão busca superar a oposição entre Heráclito e Parmênides, e ao mesmo tempo conciliar a posição de ambos. Ele soluciona o problema a partir da metafísica das formas eternas, segundo a qual a realidade sensível depende da realidade inteligível, que está acima do tempo e não encontra-se submetida à mudança que atinge as coisas temporais. O tempo, por conseguinte, é definido por Platão como “a imagem móvel da eternidade". Aristóteles, por sua vez, aponta como erro fundamental dos eleatas, entre os quais Parmênides, a suposição de que o ser se diz em apenas um sentido, e não segundo múltiplos significados distintos e não redutíveis uns aos outros. Ao propor que o ser se diz de várias maneiras (em sentido substancial, categorial, lógico, e como 
potência e ato), Aristóteles formula sua própria solução do problema do tempo e resolve a contradição entre as teorias de Heráclito e Parmênides.

No entanto, a visão do universo como fluxo, proposta por Heráclito, desperta posteriormente na história da filosofia um semnúmero de filosofias do devir, do vir-a-ser, direta ou indiretamente influenciadas pelo "obscuro" pensador de Éfeso. Entre os pensadores modernos que reabilitam a filosofia do devir encontra-se Henry Bergson.

Na sua obra A Evolução Criadora, Bergson diz que a filosofia grega se via em sérios embaraços diante da questão do tempo e começou por renunciar ao desafio de resolvê-la. Daí a decisão dos présocráticos em condenar o devir como ilusório e manter a ideia de uma realidade inteligível que não está no tempo. O mesmo espírito de recuo diante do enigma do tempo viria animar a atitude de considerável parte da filosofia ocidental.

Como o devir choca os hábitos do pensamento e dificilmente se insere nos moldes da linguagem, declararam-no irreal. No movimento espacial e na mudança em geral viram apenas ilusão. Podia atenuar-se esta conclusão sem mudar as premissas; dizer que a realidade muda, mas que não deveria mudar. A experiência coloca-nos em presença de um devir: é esta a realidade sensível. Mas a realidade inteligível, aquela que devia existir, é ainda mais real, e essa, dir-se-á, não muda. Por detrás do devir qualitativo, do devir evolutivo, do devir extensivo, o espírito deve procurar aquilo que é 
refratário à mudança: a qualidade definível, a forma ou essência, o fim (BERGSON, 1971, p. 306).

Na visão de Bergson, Platão teria feito a opção radical de só admitir uma ciência possível nos domínios da matemática e da geometria, as quais operam com essências lógicas eternas e imutáveis. O conhecimento válido, na sua visão, seria aquele que possui a precisão, a exatidão e a imutabilidade do eidos ( $\varepsilon \tilde{i} \delta \circ \varsigma)$ matemático. Para Platão, a ciência consiste num acervo unificado de conhecimentos cuja característica é a verdade e a justificação racional. Essa ciência, portanto, deve ocupar-se com aqueles conhecimentos que podem ser rigorosamente verificados e demonstrados, ou seja, aqueles que se enquadram no modelo de racionalidade matemática que opera apenas com formas abstratas. A partir dessa definição, exclui-se então da classe das ciências todos os conhecimentos que surgem da experiência porque eles estão sujeitos à ação do devir, ou seja, aparecem e desaparecem conforme a sucessão dos instantes no tempo.

Platão fundamenta sua ideia de ciência em uma realidade inteligível não atingida pela mudança que a duração imprime no mundo sensível. A investigação científica, assim, deve ocupar-se do necessário e não do contingente, ela tem um caráter lógico e não empírico. A doutrina de Platão aceita a existência de apenas quatro disciplinas científicas verdadeiras: Aritmética, Geometria, Astronomia e Harmonia. As duas primeiras de orientação puramente matemática, e as outras duas ligadas à experiência, mas que devem ajustar-se o mais 
possível ao modelo matemático das primeiras. A ciência platônica deve estudar a realidade inteligível, eterna e imutável, e não a realidade sensível, porque esta é ilusória e nossa razão aconselha não confiar no testemunho precário dos nossos sentidos. Tudo isso leva Platão a concluir que "não há ciência da natureza". Esta posição radical seria a única possível diante do problema do tempo, que parece insolúvel, uma vez que movimento e mudança opõem-se firmemente ao princípio das ciências que é buscar verdades eternas e universais.

Dessa posição, está-se sempre a um passo de radicalizar o platonismo, rejeitar o tempo como ilusão e admitir como conhecimento apenas as essências lógicas e matemáticas. A outra opção é atribuir à instância temporal a própria substância real do mundo: a verdade está no devir, na própria transformação do ser. Bergson decidiu acolher essa ideia. Ele coloca-se no ponto de vista diametralmente oposto ao de Platão e busca constituir uma filosofia do devir (devient), da duração. O tempo é um continuum de evolução que abrange todo o universo e engendra formas sempre novas e imprevisíveis. O homem, na evolução, foi constrangido a operar com a matéria inerte para sobreviver e teria assim adaptado seu pensamento aos processos mecânicos do trabalho. Sua inteligência evoluiu ajustando-se à matéria imóvel e ao mecanicismo da vida prática. Ele tanto habituou-se a manejar o fixo que só entende algo agora em termos de inércia e não de movimento. Por conseguinte, a mente humana cria uma imagem 
desfigurada do mundo porque passa a representá-lo de acordo com as exigências do trabalho. O mundo é uma oficina: daí as origens psicológicas da física matemática.

O dilema que Bergson levanta é menos quanto à possibilidade do conhecimento no tempo do que à possibilidade deste conhecimento, uma vez instituído, deformar o aspecto real do mundo e ir na contramão da meta que se punha de início de tentar explicá-lo. Isso porque a inteligência, na evolução, haveria contraído um hábito cinematográfico de pensar, de modo que todo o seu saber é constituído por meio da fixação de momentos privilegiados da duração em "formas", em “conceitos", os quais são repousos e paragens possíveis do devir. Ela tira instantâneos de momentos ao longo da continuidade, pensa o devir como uma quantidade discreta, e acomodando-se a essa atividade, já não se torna capaz de pensar a continuidade em si.

Para Bergson, a duração é indecomponível aos seus momentos, ela é irredutível às formas que o pensamento fixa. Não é possível reconstituir o devir, que está fazendo-se continuamente, com momentos já feitos compilados a partir de "pausas" da realidade movente. A filosofia grega, no entanto, decide instalar-se no imutável, por isso, busca nas formas inteligíveis "a visão estável da instabilidade" (BERGSON, 1971, p. 306). Ela prefere assim qualificar as ideias de reais, ao passo que reserva para as coisas que duram o título de irreais, como sombras ou ilusões, como projeções na "parede da caverna". A 
suposição de Bergson é de que Platão teria se abandonado aos hábitos naturais da inteligência, ao "instinto cinematográfico" do pensamento, daí seu projeto de ciência prescinde do estudo da natureza porque "o domínio físico é o domínio lógico estragado", e porque o tempo, a “imagem móvel da eternidade", seria uma oscilação indefinida, uma degradação das ideias puras que constituiriam o "equilíbrio teórico do ser" (BERGSON, 1971, p. 308-311).

A essa altura, começamos a avistar já os difíceis problemas que Husserl encontra pela frente. O tempo parece constituir o enigma dos enigmas. Haverá uma conciliação possível entre tempo e conhecimento, ou a filosofia ver-se-á sempre constrangida a escolher entre dois extremos - entre o essencialismo e o devir? Husserl designa a fenomenologia de ciência eidética, ele busca redimir as essências e a lógica pura contra o naturalismo. A redução fenomenológica inclui a redução eidética (a redução às essências) como uma de suas etapas. É possível, porém, conciliar a ciência eidética com o fato do tempo e da duração? Como, então, reabilitar o conhecimento das essências sem recair no idealismo platônico? Como, então, contornar o impasse em que a teoria de Bergson deixa a filosofia das ideias? O tempo não seria, de fato, um obstáculo ao conhecimento? Como é possível conhecer o que não cessa de mudar?

São algumas das questões que surgem logo de saída. Mas veremos que a fenomenologia se comporta em relação a elas de forma original 
sem decidir-se a favor de qualquer um dos dois extremos: do essencialismo platônico ou do devir radical. O projeto de ciência eidética, primeiramente, não é incompatível com a realidade factual do tempo, não precisa recorrer à ideia de um lugar hiperurânico ( Husserl não propõe idealizar um momento do fenômeno em detrimento dos outros. Seu método de ideação não é dessa natureza. Bergson exagera ao afirmar que o pensamento é inteiramente mecânico e só se apodera conceitualmente de formas inertes. Para Husserl, a intuição da essência de qualquer objeto é inseparável da percepção dele no mundo e, destarte, essa essência incorpora mesmo as qualidades individuais, assimétricas, inexatas, dadas na experiência sensível.

A crítica que Bergson dirige ao essencialismo não se aplica a Husserl, portanto, porque estava nos planos deste último distinguir as essências morfológicas daquelas físico-geométricas. Enquanto a exatidão, a perfeição, o rigor, pertencem à essência geométrica, a essência morfológica refere-se ao objeto da percepção, por isso, ela inclui as qualidades sensíveis dele com toda a margem de indeterminação que lhes é inerente. O objeto temporal móvel, mutável, possui assim mesmo uma essência aproximativa e vaga que consegue exprimi-lo. Vemos isto acontecer frequentemente em biologia ou geologia: o objeto sendo chamado de chanfrado, sinuoso, lenticular, escantilhado, rugoso etc. Fazemos uso de tais noções quando 
precisamos descrever algo na percepção. Husserl denomina tais conceitos de morfológicos, pois eles admitem certa margem de imprecisão, são flexíveis de acordo com a experiência.

A geometria analisa um espaço idealizado composto de figuras perfeitas: triângulos, retângulos, círculos, retas, curvas etc. O espaço da vida concreta, porém, só se deixa representar pelas essências morfológicas. Estas incluem os predicados inexatos tais como gradações de cor, de grandeza, de temperatura, elas possuem a plasticidade exigida para retratar as qualidades indeterminadas do objeto que, como tais, são assimiladas ao Eidos morfológico dele. Como diz Lévinas: “O pensamento essencial de Husserl consiste em afirmar o primado das essências inexatas, morfólogicas, sobre as essências exatas, matématicas" (LÉVINAS, 1994, p. 172). Ou seja, a essência de caráter geométrico, criticada por Bergson, é uma essência derivada. O objetivo de Husserl é determinar sua ciência eidética a partir das essências originárias que estão na base de todo conhecimento possível. A partir dessa conquista primeira sobre o idealismo platônico, veremos, daqui em diante, como a tese fenomenológica das essências se comporta em relação ao problema da temporalidade.

\section{A temporalidade imanente}

Husserl enfrenta o problema do tempo em termos diferentes daqueles da tradição filosófica. Como diz Alves (2008, p. 163), “a 
questão da consciência do tempo será reconvertida na questão da temporalidade da consciência", a qual está relacionada com o problema da possibilidade do conhecimento e solicita uma “inquirição gnosiológica (eine erkenntnistheoretische Frage) sobre a experiência subjetiva do tempo, enquanto lugar da sua constituição originária”. Husserl se empenha na busca pela origem do tempo - isso implica a necessidade de clarificar o modo de auto-constituição temporal da subjetividade, a questão da intencionalidade enquanto vivido temporal da consciência.

Para Alves, são três modalidades de visada intencional que entram em consideração na investigação husserliana do tempo:

$1^{\circ}$ as vivências pelas quais o tempo é visado (os caracteres de ato e os conteúdos primários da apreensão de tempo), $2^{\circ}$ as formas em que o temporal aparece, ou seja, é intuitivamente dado (o fenômeno da "fluência", as modalidades temporais do presente, passado e futuro), $3^{\circ}$ a constituição de um tempo objetivo uno enquanto Naturzeit e Weltzeit (os processos de idealização que conduzem à posição de um tempo do mundo) (ALVES, 2008, p. 154).

Husserl parte de uma confrontação com as teorias de Alexius Meinong e de Franz Brentano. A distinção de Meinong entre objetos distribuídos e não distribuídos temporalmente, assim como as discussões de Brentano sobre as associações originárias na constituição do "tempo-presença", iriam exercer um papel crucial na reflexão feita nas Lições. Husserl critica em Meinong, em primeiro lugar, o 
pressuposto naturalista de que o tempo e sua contínua fluência ocorrem "em si", "fora" da consciência, enquanto formações objetivomundanas, e que, em retorno, o que dele se retém na consciência é simplesmente o seu resultado morto: a pura série dos pontos-agora como justaposição de unidades atomizadas. Em segundo lugar, a convicção de que a percepção se encerra na momentaneidade do agora, ideia que, por sua vez, supõe que o agora deve ser compreendido pontualmente, como algo que se limita à fase atual de um objecto temporal.

Brentano, por sua vez, tem uma dupla tese: que a consciência do passado corresponde a uma consciência de imagem e que a diferença que existe entre presente e passado deve ser dada no próprio teor positivo do conteúdo de consciência, trata-se de uma modificação que afeta o conteúdo e o altera, e essa modificação corresponde justamente à determinação temporal. Brentano fala de "representações mnemônicas" que, operadas pela imaginação, duplicam a percepção anterior numa sucessão, voltando a reproduzi-la junto ao conteúdo perceptivo atual. O mais crucial na teoria de Brentano é a ideia de alteração de conteúdo. Quando ouvimos uma melodia, por exemplo, mantemos a "fantasia" de cada acorde já passado para associá-la com o acorde atual. $\mathrm{O}$ som que acabou de soar reaparece modificado e vem ligar-se à cadeia contínua das demais representações da música. Pois se os sons "permanecessem sem modificação, teríamos nós então, em vez 
de uma melodia, (...) uma amálgama desarmônica de sons, tal como a obteríamos se todos os sons já soados tocassem simultaneamente" (HUSSERL, 1994, p. 46).

A posição de Brentano sobre a função da fantasia como a origem de nossa representação do tempo é recusada por Husserl. Para este, o conceito de imagem confere a ela um caráter psicológico que se mostra insuficiente para descrever a temporalidade num nível mais fundamental. Enquanto a teoria de Brentano o levou a extrair a conclusão de que as modificações do objeto, no decorrer do tempo, são modificações de conteúdo, Husserl sugere que a modificação encontrase do lado da própria consciência, trata-se de uma modificação na modalidade do ato intencional. A impressão originária é modificada permanentemente, não à maneira de Brentano (modificação do conteúdo), e sim pela modificação da modalidade do ato de consciência que a tematiza. A diferença fundamental deve residir no modo de apreensão, no modo de consciência. A forma do ato, a intentio, se matiza em diferentes modalidades apreensivas, a retentio (retenção), do passado, e a protentio (protensão) do futuro, as quais produzem as determinações temporais do conteúdo.

Por exemplo, uma das modalidades da intencionalidade, a recordação, é também uma forma pela qual a consciência é consciência de alguma coisa. Tal como ocorre com a percepção, que se relaciona 
com o objeto percebido, a recordação é um modo de a consciência referir-se ao objeto sob a forma do "recordado".

A recordação é auto-presentificação no sentido do passado. A recordação presente é um fenômeno totalmente análogo à percepção, ela tem em comum com a percepção correspondente a aparição do objeto, tendo apenas a aparição um caráter modificado, graças ao qual o objeto não se nos depara como presente, mas sim como tendo sido presente (HUSSERL, 1994, p. 87).

O que determina a diferença nos modos intencionais de apreensão do tempo? Husserl fala de uma "lei de modificação constante" que transforma a apreensão do "agora" (jetzt) na apreensão de um "agora mesmo passado" (soeben). O "agora mesmo passado" preenche sinteticamente numa doação intuitiva o passado imediato e oferece o objeto temporal numa percepção global. Em cada fase do campo presente, há uma triplicidade de intenções conectadas dinamicamente. O agora mesmo passado é dado diretamente junto com o agora, e de modo intuitivo, não vazio ou simbólico. A retenção é uma forma de presentificação de caráter reprodutivo que conserva a consciência impressional anterior junto à atual. Há todo um tecido de consciências temporalmente modificadas que transcorrem no fluxo encaixando-se umas nas outras, de modo que a consciência do agora que foi é dada em unidade com a consciência do agora atual.

O exemplo da melodia é privilegiado para ilustrar tudo isso. O que permite que a audição de uma melodia, um som temporalmente 
estendido, seja um ato global de percepção, e não uma mera sequência de impressões sonoras justapostas umas às outras?

\begin{abstract}
O som começa e acaba e toda a sua unidade de duração, a unidade de todo o processo (...) move-se, depois de ter findado, para um passado cada vez mais distante. Nesta retrotração, "detenho-o" ainda, tenho-o numa "retenção", e enquanto ela se mantém, ele tem a sua própria temporalidade (...). Posso dirigir a atenção para o seu modo de ser dado. Ele e a duração que preenche estão conscientes numa continuidade de "modos" (HUSSERL, 1994, p. 57).
\end{abstract}

Podemos reparar que na transição de fase para fase do som duradouro, cada percepção limita-se a um agora instantâneo. Daí "a extensão total do som (...) jaz, por assim dizer, como qualquer coisa morta, (...) como uma formação que nenhum ponto produtor do agora anima, mas que constantemente se modifica e se precipita no vazio" (HUSSERL, 1994, pp. 57-58). Mas nenhum vivido do som, dado neste agora, é independente, ele exige um complemento, de um lado, pela retenção que conserva os sons que já-foram, que impede que eles desapareçam no fluxo heraclitiano, de outro, pelo poder de antecipação protencional, dirigido para os sons futuros. Cada som aparece inscrito sob o horizonte de fundo da melodia total. E é justamente esse panorama de fundo, duplamente estendido, que constitui a base de sentido para cada som atual. Dizer que o objeto do conhecimento é duradouro significa dizer que sua duração aparece animada e duplamente preenchida, de um lado, pelas retenções do passado e, de 
outro, pelas expectativas do futuro. De modo que a sua aparição atual destaca-se sempre de um fundo de presença global que é a melodia em sua completude.

A retenção pode ser vista como uma espécie de regente da orquestra, ela reanima os acordes que já soaram numa síntese com os acordes atuais. Todo som que inicia no modo do ponto-agora (protoimpressão) é a fase inaugural de um ponto impressional, por exemplo, o toque que inicia a melodia. Ao longo da música, qualquer momento dado guarda seu horizonte de anterioridade e estende-se, em sucessão, atualizado pelos agoras advenientes. Necessariamente, há precedência de uma proto-impressão relativamente às retenções dela. $\mathrm{O}$ ponto correspondente à proto-impressão afasta-se continuamente para um passado cada vez mais remoto. Husserl recorre a uma analogia com o distanciamento espacial: a incessante retrotração para o passado faz com que a coisa perca em nitidez: quanto mais ela contrai-se para o passado, mais ganha em obscuridade. Sem cessar, a melodia é preenchida pela série dos agoras, que de um lado escoam-se para o passado e de outro se atualizam pela chegada de um novo agora.

Uma fase impressional aí desempenha o papel de fase-limite por relação a uma continuidade de retenções; há um encadeamento (ein Ineinander) contínuo de retenção de retenções que Husserl compara a uma cauda de cometa. "A apreensão do agora é, de algum modo, o núcleo para uma cauda de cometa de retenções, respeitantes aos pontos- 
agora anteriores do movimento" (HUSSERL, 1994, p. 63). A totalidade da melodia é apreendida numa "conexão de apreensão". A cauda retencional torna possível uma ascensão ao horizonte total de fundo da melodia “à semelhança do modo como o contínuo espécie-vermelho converge para um puro vermelho ideal" (HUSSERL, 1994, p. 71).

A percepção coincide com o ponto atual que deixa apenas entrevisto um espectro do horizonte que lhe faz fundo. Pertence à essência dos vividos intencionais, entre o fato de serem "dirigidos para", "voltados para", o de se caracterizarem pela atualidade do "para", determinado pela atenção, e pela inatualidade dos horizontes que lhe fazem fundo. Tudo isso admite a possibilidade de uma modificação, de caráter notável,

(...) que faz passar a consciência do primeiro modo, no qual ela está voltada de forma atual, ao segundo modo da inatualidade, e reciprocamente. No primeiro caso o vivido é uma consciência, por assim dizer, explícita de seu objeto; no outro caso, é uma consciência implícita, puramente potencial (...) O fluxo do vivido não pode jamais ser constituído de puras atualidades (...) Mas a essência do fluxo do vivido em um eu vigilante implica, de acordo com o que precede, que a cadeia ininterrupta das cogitationes seja constantemente ladeada por uma zona de inatualidade, sempre pronta a se converter no modo de atualidade, e reciprocamente a atualidade em inatualidade (HUSSERL, 1950, pp. 114-115).

Cumpre observar também que, para Husserl, o som é um objeto temporal imanente que aparece como dado hylético. Isso permite compreendê-lo como algo a ser preenchido. Da mesma maneira como 
Husserl afastou-se da tese das associações originárias, ele admite a possibilidade da intuição da duração: "Não é, por conseguinte, tal que tenhamos uma simples cadeia de intenções 'associadas' umas às outras, recordando estas a mais próxima (fluente), mas temos antes uma intenção que é em si intenção da cadeia de preenchimentos possíveis" (HUSSERL, 1994, p. 83). Mas Husserl salienta que se trata de uma intuição não-intuitiva, vazia. A presença do objeto coincide com o agora, é simultâneo ao agora atual, assim, ele exibe uma única face e deixa por detrás toda uma totalidade sintética de pontos de aparição possíveis que lhe fazem fundo. Mas a intuição desses pontos é vazia porque supõe uma totalidade não-preenchida que permanece como pano de fundo. Essa intenção é naturalmente preenchível pelas conexões que podem se estabelecer entre os agoras. E aqui Husserl faz recurso a uma analogia com o fundo espacial que se comporta de maneira idêntica:

cada coisa tem, na percepção, o seu reverso como fundo (porque não se trata do fundo da atenção, mas sim da apreensão). (...) Não há primeiro plano sem fundo. O lado que aparece nada é sem o lado inaparente. Assim também na unidade da consciência do tempo: a duração reproduzida é o primeiro plano, as intenções de inserção (da duração no tempo) tornam consciente um fundo temporal. E, de um certo modo, isso continua na constituição da temporalidade do próprio (objeto) duradouro, com o seu agora, o seu antes e o seu depois (HUSSERL, 1994, pp. 83-84). 
Pela protensão, os pontos no horizonte estão estendidos também na direção do futuro, cuja intenção é a mesma da do passado, só que invertida. O futuro é um tipo de passado colocado do avesso. Isso esclarece a possibilidade que temos de antecipar ou de recordar $o$ futuro, por assim dizer. "É preciso considerar, além disso, a direção inversa nessas mutações contínuas: ao antes corresponde o depois, ao contínuo de retenções, um contínuo de protenções” (HUSSERL, 1950, p. 277).

Resta, então, compreender de que forma há uma única consciência para a qual o tempo se anuncia nessa diversidade de modos. O que garante a identidade do Ego em meio à variação, à inconstância e à irreversibilidade de suas experiências temporais? Husserl assinala que faz parte da essência de todo vivido o poder de ligar-se ao vivido que lhe é imediatamente posterior.

A propriedade eidética que exprime o termo geral de temporalidade aplicada aos vividos em geral não designa somente um caráter que possui de forma geral cada vivido tomado separadamente, mas uma forma necessária que liga vividos a vividos. Todo vivido real (...) é necessariamente um vivido que dura; e com essa duração ele se ordena a um contínuo sem fim de durações - a um contínuo preenchido (erfüllten) (HUSSERL, 1950, p. 275).

De acordo com Husserl, o cogito, na medida em que possui o caráter temporal, entra em permanente síntese consigo mesmo, ele se coordena de uma ponta a outra em torno do cogitatum, o objeto 
pensado. Isso significa, pois, que a síntese é a forma originária da consciência, e que a forma fundamental da síntese, por seu turno, é a identificação. O cogito se caracteriza por um modo de coordenação sintético que une os estados de consciência: as cogitationes, e, destas, diz-se sempre que se referem a um objeto intencional cuja identificação é feita ao longo da série. Da parte do cogitatum, que é o objeto transcendente das cogitationes, vemos que vale para ele também igual necessidade de coordenação, já que, em todo aparecimento, ele só pode ser apreendido numa "estrutura de multiplicidades" e "se revela (...) como unidade sintética de uma multiplicidade de modos de apresentação correspondentes" (HUSSERL, 1950, p. 115).

Husserl denomina de síntese dos estados vividos a forma de ligação essencial que une um estado de consciência a outro. Dessa síntese, segue-se ao objeto a doação de uma identidade única que reúne a multiplicidade de seus perfis (Abschattungen). A identificação do objeto, portanto, é possível na medida em que a consciência realiza a síntese de todos os aparecimentos dele no tempo (percepção visual, tátil, sonora, lembrança, representação, fantasia, expectativa), de modo que ela sabe que é do mesmo objeto que se trata em cada modalidade de apreensão. Tal síntese produz simultaneamente a tríplice unidade do cogito, das cogitationes e do cogitatum, que permanecem identicamente os mesmos em meio ao fluxo variável de suas aparições. 
Todo estado vivido tem sua duração vivida. Se se trata de um estado de consciência do qual o cogitatum é um objeto do mundo - como na percepção do cubo -, é a ocasião de distinguir a duração objetiva que aparece (por exemplo, aquela do cubo) da duração "interna" do processo da consciência (por exemplo, aquela da percepção do cubo). Essa "transcorre" em períodos e fases temporais que são suas, e que são elas mesmas apresentações, se modificando duma forma contínua, de um só e mesmo cubo. Sua unidade é aquela de uma síntese. Ela não é uma simples ligação contínua de cogitationes por assim dizer exteriormente unidas umas às outras, mas ela é a unidade de uma consciência una, e nessa consciência se constitui a unidade de uma entidade (Gegenstandlichkeit) intencional, precisamente como era a mesma entidade se apresentando de maneiras variadas e múltiplas (HUSSERL, 1953, p. 36).

Mas podemos nos certificar melhor da maneira como a consciência objetiva o cubo através da síntese, caso tenhamos em conta toda a estrutura teleológica que intervém na sua constituição. Husserl volta a evocar sempre, ao longo do desenvolvimento dessas teses, a ideia de preenchimento (Erfüllung) oportunamente escolhida para responder ao problema das intenções vazias. Devido a uma necessidade eidética, está prescrito na existência das coisas dotadas do caráter do "transcendente" que sua exibição, no espaço tridimensional, só seja possível de efetuar-se parcialmente. Isso significa, em suma, que o olhar apreende apenas um dos lados da coisa de cada vez. Assim, à medida que a consciência comparece diante do objeto, todos os perfis possíveis dele, em número infinito, estão ausentes, exceto o perfil atual. As intenções que apresentam o objeto, portanto, são na maior parte 
intenções vazias, as quais solicitam ser preenchidas. As estruturas na consciência acham-se teleologicamente orientadas em função desse preenchimento pelo qual o objeto recebe sua determinação de sentido.

A análise, pois, não deve se deixar inibir pela característica da exibição por perfis (Abschattungen) e todo o conjunto de indeterminidades que resultam dela. A consciência conta com o concurso de toda uma estrutura teleológica imanente que atua no preenchimento das intenções vazias. Assim, nas direções dadas ao curso da percepção, se oferece um horizonte intencional pelo qual a consciência antecipa os lados ainda não percebidos do objeto, realizando uma conexão da percepção presente com a percepção futura. Ela realiza a síntese das percepções já dadas com aquelas "iminentes", num processo temporal que libera em bloco todos os horizontes que compõem o objeto.

Na percepção imediata do cubo, por exemplo, o que se apresenta primeiramente aos olhos é uma pirâmide, mas Husserl mostra que o aspecto atual é remissivo sempre às faces ainda não reveladas do cubo, e a consciência se dá conta da totalidade que está presente de maneira implícita em cada uma das suas aparições.

A constituição da objetividade, porém, é mesmo anterior ao saber conceitual aqui mencionado. A consciência extrai de cada um dos horizontes do objeto seu sentido, donde pode traçar previamente as potencialidades deste e constituí-lo como um polo sinteticamente 
unificado no tempo. É essa estrutura de determinação que lhe permite constituir previamente o cubo como uma totalidade idêntica, acabada, antes mesmo de perceber nele qualidades particulares como de comprimento, cor e textura.

Husserl incrementa ainda, a propósito de tudo isso, a tese de que os dados sensuais que se perfilam junto com a coisa são animados por um núcleo de sensação hylética inerente ao vivido. Esse núcleo fornece a matéria impressional que atua na constituição da forma do objeto. É esse processo que responde pela objetivação na medida em que a coisa física é motivada pelo encadeamento das experiências perceptivas.

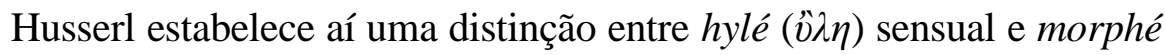
$(\mu о \rho \varphi \eta ́)$ intencional a partir de uma releitura dos conceitos tradicionais de matéria e forma. Ele reserva o primeiro dos termos, a hylé, para designar os conteúdos imanentes de sensação: os dados de cor, tato, som etc.; o segundo termo morphé, por sua vez, fica para as qualidades sensíveis: colorido, rugoso, sonoro etc., que o objeto apresenta na medida em que aparece. A camada hylética está para as qualidades sensíveis assim como a matéria está para a forma, elas são solidárias entre si.

Sobre tudo isso, impera uma estrutura teleológica imanente cujos elementos organizam-se para converter a multiplicidade das aparições sensíveis num "dado objetivo" a partir do seu preenchimento material. De onde saem importantes consequências: os vividos intencionais são 
unitários em virtude de uma doação de sentido que reúne as constantes alterações de perfil do objeto. Para a doação, a hylé contribui com a matéria que entra na formação do sentido. Essa primeira camada não é propriamente intencional, porque a consciência é consciência do objeto somente como forma, morphé ou unidade de sentido. Por conseguinte, o que entra como componente real da apreensão perceptiva é o datum de sensação que anima o vivido e lhe permite preencher as qualidades sensíveis do objeto para além dos meros esboços dele que seguem enquanto "aparições no tempo". Os momentos sensuais imanentes encontram-se em relação aos vividos concretos no papel de "uma camada que por assim dizer os 'anima', lhes dá um sentido (...); é por meio dessa camada e, a partir do elemento sensível, que em si não tem nada de intencional, que se realiza precisamente o vivido intencional concreto" (HUSSERL, 1950, pp. 288-289).

Sob o título de hylé, portanto, Husserl (1950, p. 290) se refere "aos vividos intencionais nos quais os data sensíveis das esferas consideradas se apresentam com a função de "matéria". Todo vivido comporta uma estrutura cindida, de um lado, pelos componentes propriamente intencionais e, por outro, por seus correlatos. Os primeiros componentes deixam-se afetar pela matéria impressional hylética, por exemplo, a sensação de cor, para preencher com ela o objeto correlato cujo colorido perfila-se diante deles numa sucessão de intenções vazias. Mas, além desses sentimentos sensíveis, a estrutura 
da hylé também engloba os vividos afetivos e volitivos tais como o prazer, a dor, a emoção, impulsos, desejos etc.

\section{A temporalidade do mundo}

Descrevemos acima as camadas mais originárias que fundamentam o conhecimento do tempo. Agora, como pensar a unidade da temporalidade do mundo, a temporalidade cronológica? Como o tempo objetivo, aquele que pertence à natureza e é estudado pela física, pode derivar do tempo fenomenológico com suas retenções, protensões e sínteses? Como a consciência posiciona o tempo cósmico, ou seja, aquele marcado pelo relógio, pelo calendário etc., a partir da temporalidade imanente?

Husserl só aprofundou esse ponto em trabalhos posteriores. Diz ele que, com base em idealizações como continuidade, ordem do tempo (transitividade e irreversibilidade), direcionalidade temporal em forma de flecha e infinitude, a consciência chega mediante um processo de idealização à série "total" do tempo e à sua posição como série objectiva e fixa. Isso corresponde a uma espacialização, homogeneização do fenômeno do tempo em que a totalidade dos pontos adquire uma ordem em que tudo se torna absolutamente simultâneo no mesmo horizonte multilinear.

Para isso, Husserl complementa a ideia de síntese temporal, pela qual a consciência se relaciona intencionalmente consigo mesma, com 
a ideia de uma síntese universal que "torna possíveis todas as outras sínteses da consciência", de onde se segue a conclusão de que "cada estado individual que podemos conceber não emerge senão sobre o fundo de uma consciência global, unificada, que ele pressupõe sempre" (HUSSERL, 1953, p. 37). A ideia de síntese total, unificada, remete afinal àquela de um cogito universal "que abraça de maneira sintética todos os estados de consciência individuais podendo emergir dessa vida, e que tem seu cogitatum universal, fundado de maneiras diferentes sobre múltiplos cogitata particulares" (HUSSERL, 1953, p. 37).

Esse cogitatum universal, portanto, inclui o tempo da natureza integralmente objetivado do ponto de vista da consciência que o constitui. Alves, buscando esquematizar as análises sobre os cogitata de Husserl, conclui que o cogitatum universal culmina de duas espécies de operações: $1^{\circ}$ - as "operações constitutivas da forma serial"; $2^{\circ}$ - as “operações constitutivas do tempo como série fixa". As primeiras são aquelas de cujo resultado sobressai "a figura de um tempo objetivo como série linear de posições temporais fixas" (ALVES, 2008, pp. 166167). Essa figura possui quatro características centrais: a continuidade serial dos pontos, a ordem (não-simetria e transitividade de um ponto para outro), a direção (do antes para o agora, do agora para o depois) e a infinitude do tempo (progressão ou regressão indefinidamente continuável). Daí a derivação do tempo medido pela régua, o tempo 
geométrico. A segunda espécie de operações, por sua vez, aponta para uma invariância fundamental ao longo dessa série mensurável que fixa ou enrijece o continuum ininterrupto das situações temporais numa situação única válida universalmente ${ }^{3}$.

A ordenação sintética dos estados de consciência tende assim para uma homogeneização dos pontos temporais que totaliza a série. Chegase assim a uma ideia de unidade universal de todos os objetos. $\mathrm{O} \mathrm{Eu}$ torna o mundo um objeto ideal sob a forma de uma "infinidade espacial e temporal" (HUSSERL, 1953, p. 31) que permanece como horizonte de fundo, único e idêntico, sobre o qual se projetam todas as flutuações de nossa vida cotidiana. De toda essa argumentação emerge para Husserl o fato de que "a subjetividade transcendental não é um caos de estados intencionais" (HUSSERL, 1953, p. 46). Faz parte da essência do vivido o ordenar-se em relação a outro vivido, e assim indefinidamente. E embora o encadeamento total não seja suscetível de se dar numa intuição única, o complemento de um vivido por outro se caracteriza pela "ausência de limites". Husserl, nas Meditações Cartesianas, chama a ideia de totalidade que resulta disso de uma “ideia reguladora infinita” (HUSSERL, 1953, p. 46), e é esclarecedor quando diz ainda, nas Ideias Diretrizes para uma Fenomenologia, que se trata de uma “Ideia no sentido kantiano" (HUSSERL, 1950, p. 280).

\footnotetext{
${ }^{3}$ Para mais detalhes sobre o assunto, consultar o artigo completo do professor Pedro Alves: Tempo Objetivo e Experiência do Tempo: A Fenomenologia husserliana do Tempo perante a Relatividade Restrita de A. Einstein.
} 
Passemos agora para a recepção crítica dos resultados que Husserl alcançou nas Lições sobre o Tempo. Paul Ricœur, nas conclusões de seu livro "Tempo e Narrativa", apontou pelo menos três aporias na teoria husserliana. Em primeiro lugar, existe a relação supostamente aporética entre uma experiência de tempo subjetiva e uma ordem de tempo fixa e objetiva; em segundo lugar, a falta de justificativa para a suposição da unidade do tempo e, em terceiro, a suposta impenetrabilidade da origem do tempo nas camadas mais profundas da consciência.

Além disso, o modelo husserliano de um tempo objetivo homogêneo e infinito é reconhecidamente baseado em um conceito newtoniano de tempo, e corresponde também à noção do senso comum. Um problema a ser colocado é: em que medida ele corresponde, de fato, ao tempo do mundo? Pois a noção se choca claramente com os resultados alcançados por Einstein no artigo de 1905 Eletrodinâmica dos Corpos em Movimento, particularmente, com a teoria da Relatividade Restrita, para a qual não há um tempo, mas uma multiplicidade de tempos, as medidas são sempre relativas a um observador, a grandeza “tempo" está sempre dependente da fixação de um ponto de vista (de um referencial) e da transformação ordenada dos pontos de vista uns nos outros mediante operações geométricomatemáticas, característica que leva à impossibilidade de uma determinação unívoca do tempo. Por outro lado, vários estudiosos, 
como Oskar Becker, Herman Weyl, destacaram o potencial que a fenomenologia tem na fundamentação gnosiológica da física. Justamente por causa dessa lição última da relatividade de que não passamos ao tempo da Física por supressão da subjetividade e pela instalação numa visão "sem ponto de vista", mas por um jogo de conexões e transformações entre as múltiplas experiências subjetivas do tempo.

\section{Referências}

ALVES, Pedro M. S. Tempo objetivo e experiência do Tempo: a fenomenologia husserliana do Tempo perante a Relatividade Restrita de A. Einstein. Investigaciones Fenomenologicas 6, 2008.

BERGSON, Henry. A Evolução Criadora. Tradução de Adolfo Casais Monteiro. Rio de Janeiro: Opera Mundi, 1971.

HUSSERL, Edmund. Idées directrices pour une phénoménologie. Traduit de 1'Allemand par Paul Ricœur. Paris: Éditions Gallimard, 1950 .

- Lições para uma fenomenologia da consciência interna do tempo. Tradução de Pedro M. S. Alves. Lisboa: Imprensa Nacional Casa da Moeda, 1994.

- Méditations Cartésiennes. Traduit par

Gabrielle Pfeiffer et Emmanuel Lévinas. Paris: Librairie Philosophique J.Vrin, 1953. 
LÉVINAS, Emmanuel. Théorie de l'Intuition dans la Phénoménologie de Husserl. Paris: Libraire Philosophique J.Vrin, 1994.

Data de registro: $12 / 08 / 2020$

Data de aceite: 08/01/2021 